\title{
SIMULATING THE MAGNETRON SPUTTERING PROCESS FOR INDUSTRIAL APPLICATIONS
}

\author{
Ionuţ Spătaru, Adrian Nicolescu, Cezara Coman, Cozmin Cristoiu, Andrei Ivan \\ Faculty for Engineering and Management of Technological Systems, Politehnica University of Bucharest, Splaiul \\ Independentei 313, Bucharest 060042, sector 6, Romania
}
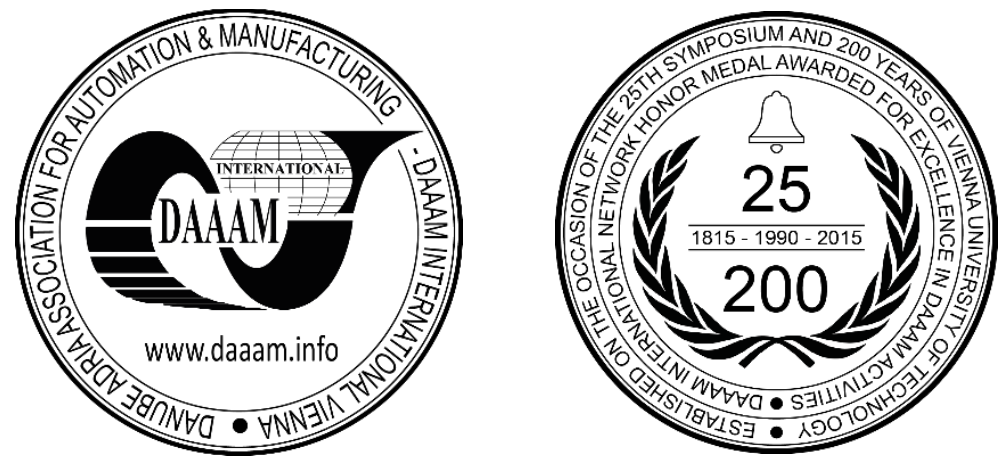

This Publication has to be referred as: Spataru, I[onut]; Nicolescu, A[drian] F[lorin]; Coman, C[ezara]; Cristoiu, C[ozmin] \& Andrei, I[van] (2016). Simulating the Magnetron Sputtering Process for Industrial Applications, Proceedings of the 27th DAAAM International Symposium, pp.0827-0837, B. Katalinic (Ed.), Published by DAAAM International, ISBN 978-3-902734-08-2, ISSN 1726-9679, Vienna, Austria

DOI: $10.2507 / 27$ th.daaam.proceedings. 120

\begin{abstract}
This paper presents a new method of simulating the process of thin layer glass coating by magnetron sputtering on real industrial scale equipment and in real industrial application as well as necessary experimental results for the validation of the new developed mathematical formulation and software algorithm. Based on major differences between applications realized with laboratory equipment studied until now by other authors and the real scale industrial installations analyzed in present paper, development of a new mathematical model, simulation method and process control of magnetron sputtering systems by ionized physical vapor deposition (IPVD) was needed. Improvement of the deposition process by applying this new concept on industrial scale is discussed for different material types, specific deposition energy levels and the uniformity of the deposed layers based on simulation and experimental results analysis.
\end{abstract}

Keywords: magnetron, sputtering, industrial scale equipment, modeling, simulation, experimental tests.

\section{Introduction}

At the moment there are two known techniques for applying thin metallic layers on glass: by vapor deposition in chemical / physical phase (CVD - Chemical vapor deposition / PVD - Physical vapor deposition). These methods are also called "on-line method" respectively "off-line method". On-line method involves glass coating during its pyro-lytic production process (spreading of the melted material on the hot glass floating in the oven on a tin bath) and represents the process by which a thin layer is applied to the glass by CVD. In contrast to this, off-line method is applied after the glass has been produced, using a magnetron and by vacuum deposition in PVD methods, usually sputtering type.

In terms of a comparative analysis of the two deposition methods, in general, off-line / PVD method has as main advantages the widest range of options for covering materials and superior optical performance of the coated glass against on-line / CVD method. As main disadvantages offline method is characterized by increased lead times and color variability between batches.

For this reason most of the industrial research efforts are focused on improving operating performances of magnetron sputtering PVD type equipment, with special focus on analyzing the possibilities of optimization of PVD process parameters for industrial production, in accordance with the desired performance to be obtained for different product categories and their reproducibility for multiple manufacturing batches. How this research is marked by the existence of 
a serious competition both between companies producing magnetron sputtering PVD type equipment as well as between their users (manufacturers of coated glass products), in the related literature there is an extremely low number of information regarding such researches [1].

But unlike the absence of such studies, in the related literature are presented a big number of studies on the development of theoretical and experimental researches conducted on pilot production equipment and experimental research laboratory facilities. Unfortunately a large number of theoretical and experimental results presented in such studies, although contribute to founding of PVD processes, are not applicable in industrial production processes. because laboratory machines / research equipment have different characteristics than industrial scale production machines / equipment. [1]

Taking into account above aspects, this paper presents a part of theoretical and experimental research developed along first author's $\mathrm{PhD}$ thesis elaboration, by using a new approach for simulating the operation of magnetron sputtering PVD equipment for industrial applications. The major goal of this research was to create and experimentally validate a new software simulation environment for the magnetron sputtering PVD processes performed at industrial scale by means of flexible manufacturing lines for glass coating.

\section{Current state of magnetron sputtering theoretical and experimental researches}

Magnetron sputtering uses a PVD technique for deposition of metallic layers also called as "spraying" and consists in applying layers of metal oxide, in vacuum conditions on glass substrates. This process allow obtaining a wide range of products with different formulas / number of layers deposited on the glass substrate, and different thickness variations of the layers of deposited metal materials. As a result of this deposits one of the well-known properties of the so treated glass is the ability to reflect different types of solar radiation (ultraviolet, infrared etc.), as are the glass products from the "Low class", necessary for sun protection of enclosures used in warm climates as well as those that require improved heat insulation. For each product of this type should be used specific manufacturing "formulas" depending on a large number of process parameters. From this point of view existing studies in the related literature describe in detail almost exclusively only glass processing on laboratory magnetron sputtering equipment or pilot manufacturing facilities with a small number of production cells (usually 1 or maximum 2 cells). [1]

Two variants of such kind of specific systems for research developed in laboratory are presented below.

\subsection{Research on laboratory equipment for experimental study of magnetron sputtering facilities}

A synthesis of the related literature regarding existing studies for modeling the phenomena that occur in magnetron sputtering equipment is presented in table 1, highlighting the influence of main factors affecting this process. [2].

Table 1 [2] presents mainly interactions that occur on target surface in magnetron sputtering process (see also fig 1, [3]) included formulas highlighting the complexity of physical phenomena occurring in such facilities. To simulate the process unfolded in the industrial environment, the mathematical models based on simulation of such installations must include all these interactions, so becoming very complicated and impossible to be practically used.

\begin{tabular}{|c|c|c|}
\hline Description & Formula & Unit \\
\hline Surface binding energy & $U_{s b}=\left(\Delta_{f u s} H+\Delta_{v a p} H\right) \Delta N_{a}$ & $\mathrm{eV}$ \\
\hline Energy transfer mass factor & $\Gamma=4 m_{p} m_{r} /\left(m_{p}+m_{r}\right)^{2}$ & dimensionless \\
\hline Average energy of recoil & $E_{a v e}=U_{s b} \ln \left(\gamma \mathrm{E} / U_{s b}\right)$ & $\mathrm{eV}$ \\
\hline Thomas- Fermi screening length of projectile & $a_{p}=0.8853 a_{0} /\left(Z_{p}^{\frac{2}{3}}+Z_{r}^{\frac{2}{3}}\right)^{1 / 2}$ & $\mathrm{~A}$ \\
\hline Thomas- Fermi screening length of recoil & $a_{r}=0.8853 a_{0} /\left(2 Z_{r}^{\frac{2}{3}}\right)^{1 / 2}$ & $\mathrm{~A}$ \\
\hline Reduce energy of the projectile & $e_{p}(E)=\left[\frac{a_{p} m_{r}}{Z_{p} Z_{r} q^{2}\left(m_{p}+m_{r}\right)}\right] E$ & dimensionless \\
\hline Reduce average energy of recoil & $e_{a v e}(E)=\left[\frac{a_{r}}{Z_{p}^{2} q^{2}}\right] E_{a v e}$ & dimensionless \\
\hline Nuclear stopping power of the projectile & $\frac{d E}{d R \uparrow_{n p}}=S_{n p} n_{t}$ & $\mathrm{eV} / \mathrm{A}$ \\
\hline Nuclear stopping power for recoil & $\frac{d E}{d R \uparrow_{n r}}=S_{n r} n_{t}$ & $\mathrm{eV} / \mathrm{A}$ \\
\hline Range of the projectile & $R_{p}(E)=E /\left(\frac{d E}{d R \uparrow_{n p}}\right)$ & $\mathrm{A}$ \\
\hline Range of the recoil & $R_{r}\left(E_{a v e}\right)=\left(E_{a v e}-U_{s b}\right) /\left(\frac{d E}{d R \uparrow_{n p}}\right)$ & $\mathrm{A}$ \\
\hline Numbers of recoils & $N=E / E_{a v e}$ & dimensionless \\
\hline Efficiency (Yield) & $\mathrm{Y}=\mathrm{N}\left(R_{p} / R_{r}\right) 1 / 4$ & $\mathrm{dimensionless}$ \\
\hline
\end{tabular}

Table 1. Equations that describe the collisions at the target surface [2] 


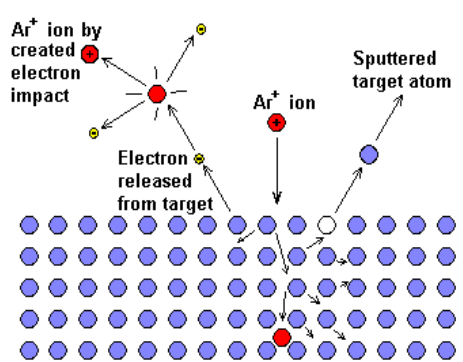

Fig. 1 Collision at target surface [3]

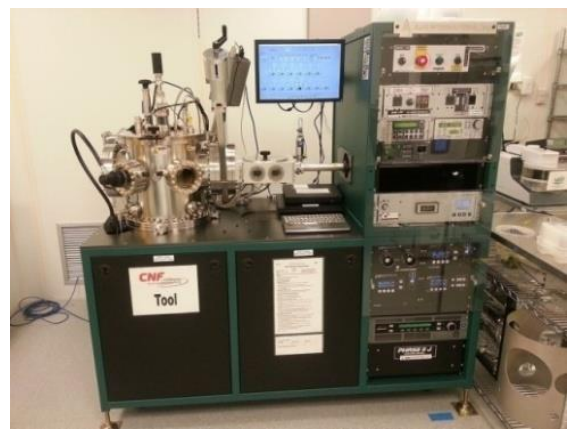

Fig. 2 Magnetron sputtering laboratory research equipment [4]

In fig. 2 the complexity of an experimental facility (an AJA Orion sputtering system) from a research laboratory (Cornell Nano-Scale Science and Technology Facility) can be observed too [4]. This equipment comes with a lot of sensors that can provide accurate values not only for the experiment results, but also for trajectory of all ions of sprayed elements. In addition the input parameters control is completely determined. A big plus that laboratory facilities have is that they transmit only one wave of energetic charged ions allowing to perform individual spraying, being able to identify precisely the full set of process parameters and offering the possibility to analyze carefully the results of developed experiments [3], [4].

Unlike these laboratory facilities, in industrial environment : spraying is continuous and is made with multiple cells for materials deposition in different process conditions; the outcome of multiple sprays on the same substrate can be observed only cumulatively by optically measuring the characteristics of the resulted deposed material layers [1].

\subsection{Research on laboratory pilot installations for glass processing with magnetron sputtering}

A laboratory pilot installation for glass processing with magnetron sputtering (for multilayer coating deposition on both sides of the sheet glass) is presented in fig 3. For oxide coating the method of magnetron reactive sputtering on AC current is used. For getting high economic benefits, rotary magnetrons with metal and ceramic targets are used. For quality monitoring, optical methods of measuring the spectral characteristics of transmission and reflection are applied. Modeling the coating structure and the subsequent reproduction of these parameters in vacuum machine allows receiving very good coating quality on large area glass sheets. [5]

Laboratory (pilot) manufacturing line, UV100 [5] (fig. 3), is a coating equipment consisting of three rooms: the load module, deposit module and coating module. The modules are distinguished by gates that serve as valves, each individual module having a pressure up to $2 \times 10^{-5}$ torr. The pumping system is based on turbo-molecular pumps which removes the possibility of oil contamination. In addition, the use of turbo-molecular pumps is suitable for stable pumping rate in the range of pressures, necessary for the magnetron spray process. [5] The loading module is used to load and unload the glass sheet and for pumping before entering in the deposition area. The deposit module comprises two rotatable cathodes, placed on one side of the module and three planar cathodes, installed on the other side. This makes possible to install up to 5 different target materials for deposition. The maximum length of the objects that can be coated is $800 \mathrm{~mm}$. The deposition module is maintained at a constant pressure of de $2 \times 10^{-5}$ torr, which ensure the elimination of any atmospheric contamination. [5]. For the pre-treatment of the sub-layer, an ion source is used with an energy up to $1000 \mathrm{eV}$. On the machine presented in fig. 3 gas distributors are applied, allowing production of gas and controlled flowing along magnetrons length. The flow control is important as other studies have shown, the structure of thin films deposited by magnetron sputtering being characterized by a function of gas flow and film thickness. [10] The machine is equipped with a box that generates vacuum. The box has a variable speed travel. Sources of power on the vacuum machine may be DC or AC power supplies. [5]

Developing a working software environment for accurate simulations using such systems is however very difficult, because pilot installations have a limited number of cell deposition (usually 1 maximum 2) compared to industrial production facilities that have usually 7, 15 or 22 deposition cells, and because each manufacturing line type has a specific construction, characteristic functional parameters and different control possibilities. [1]
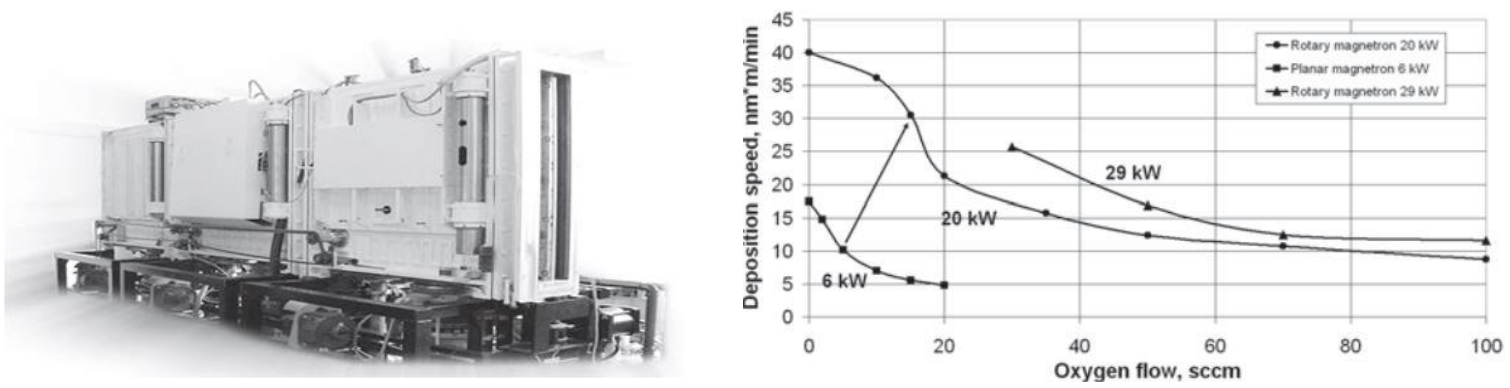

Fig. 3.Laboratory pilot line UV100 [5] Fig. 4. Deposition speed of TiO2 at different powers and oxygen flows [5] 
As concerning the experimental results obtained by using this facility, in Figure 2 the dependences of deposition speed for titanium oxide in case of different powers and oxygen flows are presented. The experiments were conducted on planar and rotary magnetrons by the length $800 \mathrm{~mm}$. From experimental data it may be seen that the rotary magnetrons makes it possible to increase the deposition rate by several times as the planar magnetrons, similar results being obtained for deposition of silicon oxide.[5]

\subsection{Mathematical modeling of specific processes for magnetron sputtering}

Most of the current theoretical models and simulations environments for magnetron sputtering are based on the formulas developed by P. Sigmund [6], the most used simulation model based on Sigmund's formulas being the Monte Carlo simulation algorithm. Simulating the thickness profile of sputtered layers not only compels the simulation of the transport through the gas phase but also the knowledge of the initial properties when the particles leave the target. [9]

This algorithm / simulation model covers the process in terms of energy transfer in the system and the characteristics of used materials.

$$
Y(E)=\frac{0.04}{U} \alpha(M t / M i) \operatorname{Sn}(E)
$$

Sn (E) - the energy of the surface collision (energy lost in the impact of molecules);

$\mathrm{U}$ - the energy of sublimation.

$$
\operatorname{Sn}(\mathrm{E})=85 \frac{Z i Z t}{\left(Z i^{\frac{2}{3}}+Z t^{\frac{2}{3}}\right)^{0.5}} * \frac{M i}{M t+M i} \operatorname{Sn}(\varepsilon)
$$

$\mathrm{Sn}(\varepsilon)$ is a function of ion energy reduction and is constant for each combination of ion and target.

$$
\begin{aligned}
& \operatorname{Sn}(\varepsilon)=\frac{3.441 \sqrt{\varepsilon \ln (\varepsilon+2.719)}}{1+6.355 \sqrt{\varepsilon}+\varepsilon(6.882 \sqrt{\varepsilon}-1.708)} \\
& \varepsilon=\frac{0.03255}{\mathrm{ZiZt}^{2}\left(\mathrm{Zi}^{\frac{2}{3}}+\mathrm{Zt}^{\frac{2}{3}}\right)^{0.5}} * \frac{\mathrm{Mt}}{\mathrm{Mt}+\mathrm{Mi}} \mathrm{E}
\end{aligned}
$$

The model is completed by total efficiency evaluation by formula:

$$
\mathrm{Y}(\mathrm{E})=\frac{0.04}{\mathrm{U}} \alpha\left(\frac{\mathrm{Mt}}{\mathrm{Mi}}\right) 85 \frac{\mathrm{ZiZt}}{\left(\mathrm{Zi}^{\frac{2}{3}}+\mathrm{Zt}^{\frac{2}{3}}\right)^{0.5}} * \frac{\mathrm{Mi}}{\mathrm{Mt}+\mathrm{Mi}} \frac{3.441 \sqrt{\varepsilon \ln (\varepsilon+2.719)}}{1+6.355 \sqrt{\varepsilon}+\varepsilon(6.882 \sqrt{\varepsilon}-1.708)}
$$
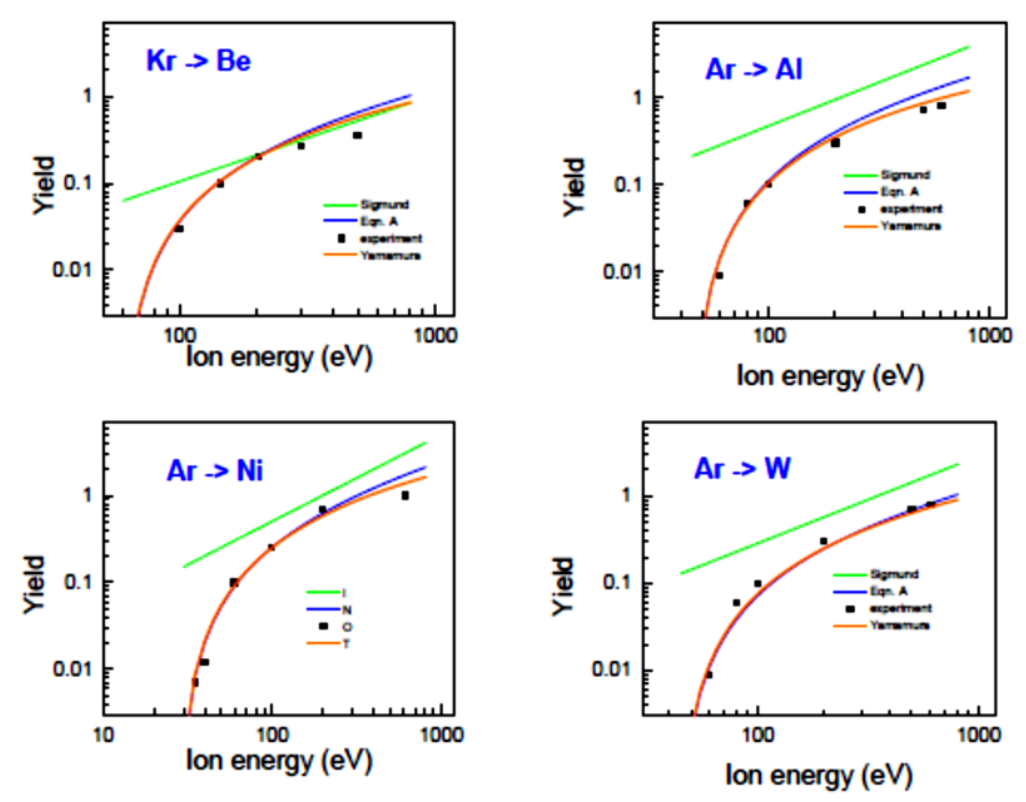

Fig. 5. The experimental measurements and theoretical based on Monte Carlo model [6] 
However, Sigmund's equation and model based on that equation is treating the process like a single interaction between one particle and the target material like is presented in fig. 5 [6].In fig. 5 it can be seen that the results obtained by using this mathematical model are characterized by following issues: different low levels energy in the system (green line represents the results predicted by Sigmund's equation and blackheads are the real values obtained experimentally). Increasing system's energy, the values obtained from simulation are more accurate.[1] Thus, generally speaking, studies involving real industrial scale magnetron sputtering machines, characterized by energies levels much higher than those presented in fig.5, may be performed by using similar mathematical formulations and may be expected to conduct to an increasing accuracy of the simulation results.[1] That is why the model created by Sigmund underlies most simulation models further developed in the literature and is also experimentally verified. However, this model cannot be directly applied in the industrial environment for studying the phenomenon as the interaction of a single particle and individual spraying procedures because in the real industrial scale machines the magnetron interaction appears in different processing environments, the substrate deposition is exclusively performed by using multiple spraying procedures as well as the magnetron sputtering process being usual in continuing operation for several days. [1]

\section{Conceptual and operational specificities of industrial installation for glass deposition by magnetron sputtering for which mathematical model was developed and software simulation for deposition process performed}

\subsection{Specific conceptual features of the flexible manufacturing line for thin layer glass deposition by magnetron sputtering}

In fig 6 is shown the real industrial scale flexible manufacturing line for thin layer glass coating by magnetron sputtering process, for which has been developed the mathematical model and the software simulation environment of the deposition process. The flexible manufacturing line is an "Apollon" type production line [7] - designed and supplied by Leyboldoptics Company - for deposition of nanometric layers by magnetron sputtering process, being installed in Saint-Gobain Glass production facility located in Călăraşi, Romania (fig.6). [7]

Processing area of Apollon system [7] consists of flexible manufacturing cells allowing the production of different coating layers on glass. The divided modular design is focused on individual cells, each of them being a standardized spraying environment. Thus, each unit of the line become a flexible manufacturing cell integrated into the flexible manufacturing line by joining all flexible cells through the same transfer and transport integrated system (fig. 6) [7].

The flexibility of the system is very important to create all the necessary new coatings especially for architectural glass, used in building facades. Reconfiguration of the system is easy to be achieved, in order for both, to maximize flexible manufacturing line productivity and as well continue extend the products portfolio.

This technological process is very suitable for the study of interactions through a flexible manufacturing process due to the specific of magnetron deposition method. The industrial installation includes a series of manufacturing cells, (it can reach a number of 200 interconnected units) all of them making successive deposits on the same substrate represented by plane glass with dimensions that can vary from $2,1 \mathrm{~m} \times 3.21 \mathrm{~m}$ up to $6 \mathrm{~m} \times 3.21 \mathrm{~m}$. In each flexible manufacturing cell the deposition can be made using the same materials and gases as in previous cells in order to get a very high productivity of the manufacturing line or respectively by using totally different materials and gases in order for obtaining products with a high complexity of deposited layers (fig 6 and fig.7) [1], [7].

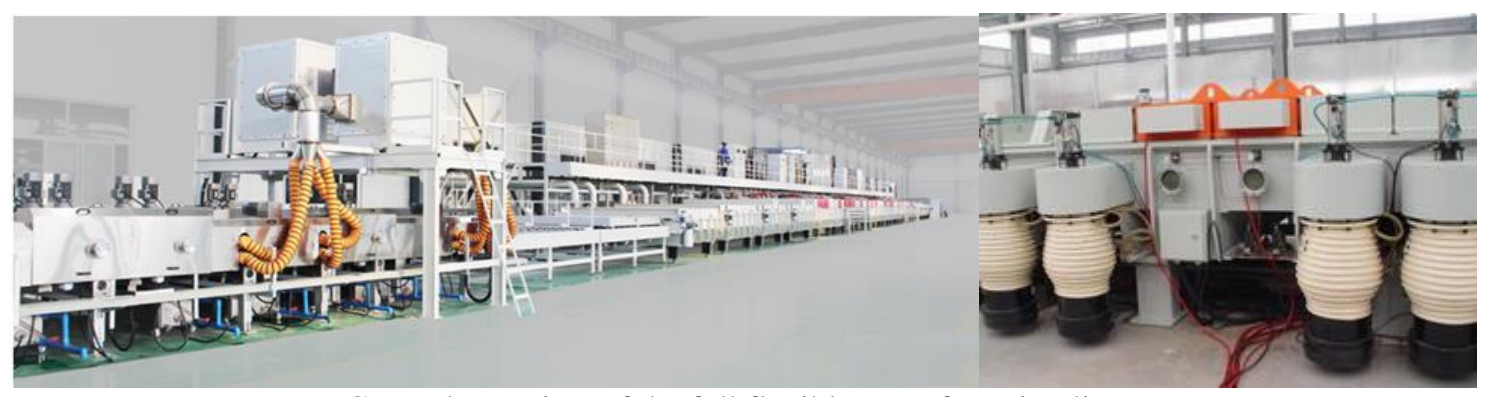

a. General overview of the full flexible manufacturing line [7]

Fig 6 Real industrial scale flexible manufacturing line for thin layer glass coating by magnetron sputtering process [7]
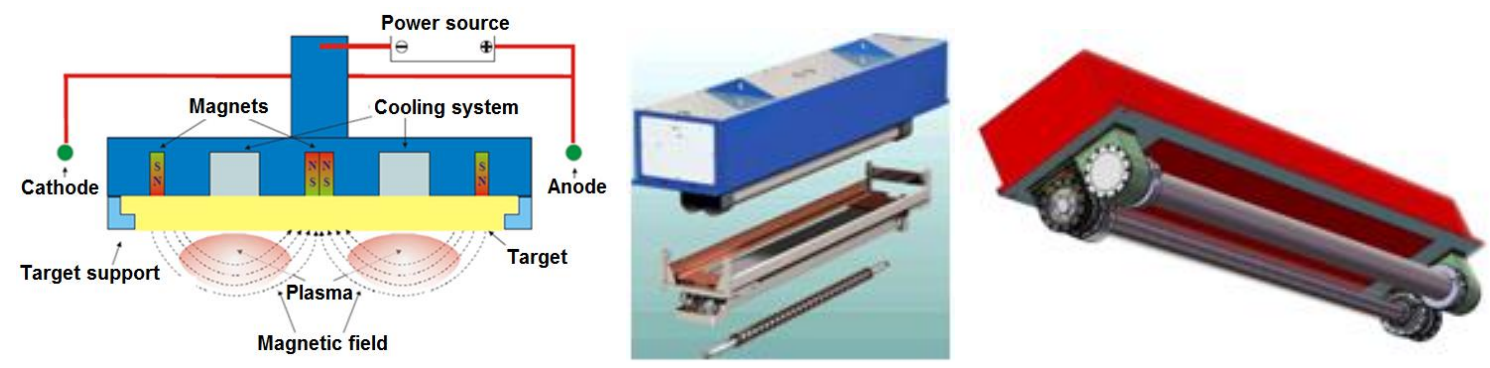

Fig 7 Functional principle, real industrial processing unit and virtual prototype of a flexible cell from the flexible manufacturing line for thin layer glass coating by magnetron sputtering process [1], [7] 
3.2. Operating principle of the flexible manufacturing line for thin layer glass coating by magnetron sputtering process. Specific parameters in magnetron sputtering processes. Particular procedures in adjusting the thin layer's homogeneity by mean of process parameters' adjustment

Flexible manufacturing lines for thin layer deposition by magnetron sputtering consists in an assembly of flexible manufacturing cells. Each cell can have a deposition process that can be totally different from the previous due to: target type, reaction gases, input power, source type (fig.8) [1].

The sistem is composed by cells that performs succesive material depositions on a sublayer, in this way the layer deposited by the first cell becomes a sublayer for the second cell depositon. Each cell is a sandalone manufacturing system with it's own parameters and those are: G1 is the reaction gas type introduced in the system, P1 is the flow and in consequence the pressure of the gas injected on the main pipe, $\mathrm{P} 2$ is the flow from the secondary pipes, A1 is the input energy amperage, M1 is the material to be deposited in cell process (fig.8) [1].

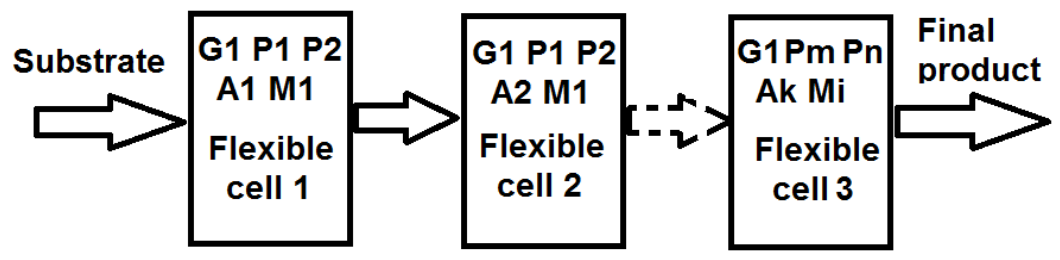

Fig.8 Operating principle and specific processing parameters setting for flexible manufacturing line / cells [1]

A table (Table 2) [1] for system influences was built to show how a material layer deposition can be controlled and manipulated. This table is valid only for a single cell; the process being repeated every time a glass sheet passes through the manufacturing cell. This table describes how the simulation that must be realized should be able to provide exact values for regulating and control of deposition rate of each manufacturing cell from the system. In table 2 are presented in the left side different typologies of the deposition profile that can result from the reaction. In the column called "corrective action to adjust thin layer homogeneity" reaction factors are presented and the way in which those must be modified to improve the profile homogeneity.

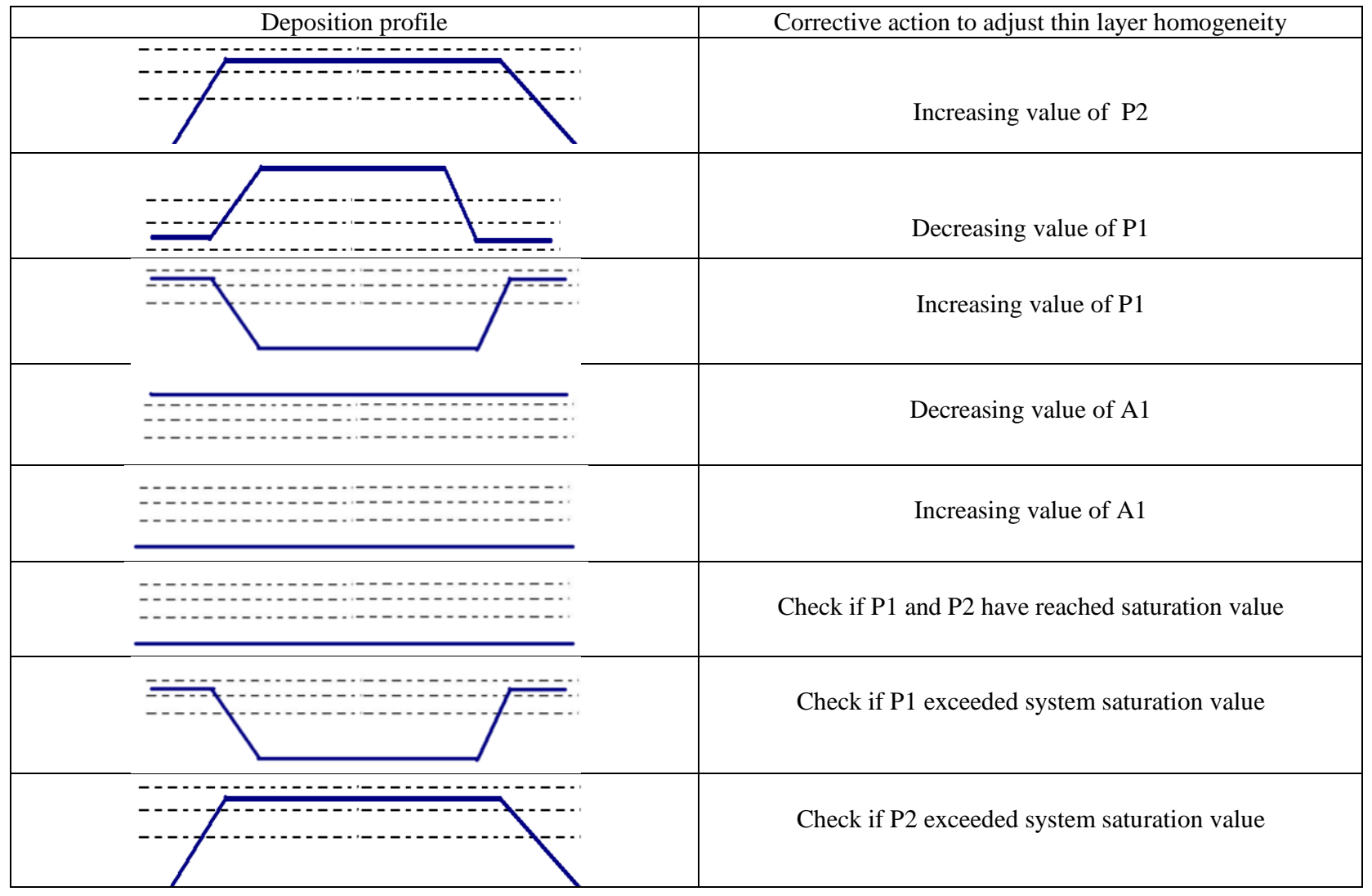

Table 2. Specific stages in adjusting thin layer homogeneity in magnetron sputtering deposition [1] 3.3. Thin layer deposition uniformity control: the international system for color identification CIELAB ("CIE $\left.L^{*} a * b *\right)$ 
The original mathematical model further presented in the paper is compatible with the international system for color identification CIELAB ( $\left.L^{*} a^{*} b^{*}\right)$ illustrated in fig. 9, this compatibility being necessary for experimental results comparison by mean of the specific investigation technique and characteristic values supplied by an electro photometer.

CIE $\mathrm{L}^{*} \mathrm{a}^{*} \mathrm{~b}^{*}(\mathrm{CIELAB})$ is a spherical color space specified by International Commission for Illumination (France "CIE") [8]. This spatial color identification system describe all visible colors for the human eye that has been specially created to serve as an independent device (and in the meantime reference element) in color evaluation.

The three coordinates of the CIELAB color space represents the color luminosity as follows: $\mathrm{L}^{*}=0$ for black şi $\mathrm{L}^{*}=$ 100 indicate the white diffuse light; - $\mathrm{a}^{*}$ characterize the color included between red and magenta: $\mathrm{a}^{*}$ is corresponding to red color in case of positive values and to magenta color in case of negative values; $b^{*}$ characterize the color included yellow and blue: $b^{*}$ is corresponding to blue color in case of negative values and yellow in case of positive values.

However, as a 3D model CIE L* $\mathrm{a}^{*} \mathrm{~b}^{*}$ may be correctly represented only in spatial (3D) coordinate system, the 2D dimensional representation being able to include only chromatic diagrams [8]. The most used coordinate system to represent CIE L* $\mathrm{a}^{*} \mathrm{~b} *$ is the spherical coordinate system, as an alternative mean, less used, being possible to appeal too on a cylindrical coordinate system.

\subsection{The flow chart for thin layer glass coating by magnetron sputtering process simulation and experimental research}

Based on the manufacturing flow presented in fig. 8, on the influences table (Table 2) and on the previously presented conclusions the logic scheme of magnetron manufacturing process was built in fig. 10. The parameters are introduced in the simulation and the program calculates de dimension of the deposition layer and if it is homogenous. Following experimental research was conducted on the same logic algorithm.

A first advantage of this working method with the simulation preceding the experiments on the manufacturing line is that different parameters sets can be tested without losses due to system stops or consumption of materials and energy, respectively rejection of some product batches as non-corresponding.

The second step is comparing the simulation results with the results desired to be obtained through experiment and analyze of performance parameters level characterizing coated material layer obtained through simulation / to be deposited effectively on glass sub-layer in experimental manufacturing processes. If from the simulation results that the coated layer is not homogenous, initial parameters adjusting must be done according to Table 2 procedures. If from the simulation results that the coated layer is uniform then the gases distribution is also uniform and can proceed to the next step of simulating the technological processes.

The next step is checking if the layer thickness matches the desired thickness. If the layer thickness is smaller than the one necessary for the product, correction procedures presented in Table 2 must be applied, process parameters values being adjusted iteratively until the desired effect is obtained.

This process is repeated for each parameter of each manufacturing cell, simulation time being influenced by de the complexity of the desired product (how many material types and gases are used in the process), and also by the number of cells used to obtain the final product.

After the possible materials with specified thicknesses have been identified, in the fourth stage the program is mixing this data. This way is obtained both necessary layer thickness and in layer position of material.

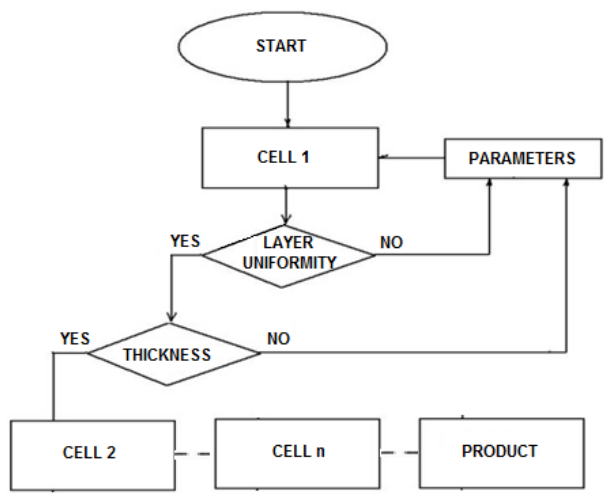

Fig. 10 Simulation flow chart

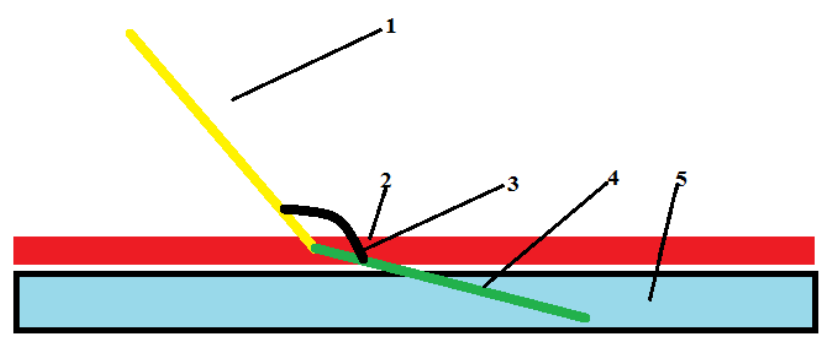

Fig. 11 Light beam path

\subsection{The core original mathematical model used for thin layer glass coating by magnetron sputtering process simulation and experimental research}

The model created by Sigmund [6] underlies the most simulation models in the specialty literature, experimental developed and checked. This model cannot be directly applied in the industrial environment because it studies the phenomenon as an interaction between a single particle and the sputtering environment being useful only in case of modeling some experiments on lab equipment. 
Using the same principles developed in Sigmund equations but adapted to the specifics of industrial processes, equations (6), (7) and (8) [1] have been developed. Thus the equations, (6), (7) and (8) describe the core of the original mathematical model created for simulation of industrial system.

The core of the new original mathematical model consists primarily in viewing the process from the point of view of the layer deposited on the precedent sub layer and not from the point of view of a particle and its interactions with the magnetron sputtering process environment. The second and most important change that the mathematical model's equations include is the identification of color values of light passing through the deposited layers of glass based on CIELAB standard. These improvements are necessary both for proper implementation in simulation model of the real industrial scale processes parameters / procedures and evaluation standards, as well as for experimental validation of mathematical formulations by experimental results obtained by performing magnetron sputtering process in industrial environment.

$$
\begin{aligned}
& \mathrm{L} * \mathrm{c}=\left[116 \mathrm{f}\left(\frac{Y}{Y n}\right)-16\right] *\left\{\mathrm{n} *\left[\mathrm{P} *\left(\frac{\mathrm{D} \text { plasma gas } * \mathrm{~d} 1}{D \text { reaction gas } * \mathrm{~d} 2}\right)\right]\right\} \\
& \mathrm{a} * \mathrm{c}=\left[500\left[\mathrm{f}\left(\frac{X}{X n}\right)-\mathrm{f}\left(\frac{Y}{Y n}\right)\right] *\left\{\mathrm{n} *\left[\mathrm{P} *\left(\frac{\mathrm{D} \text { plasma gas } * \mathrm{~d} 1}{D \text { reaction gas } * \mathrm{~d} 2}\right)\right]\right\}\right. \\
& \mathrm{b} * \mathrm{c}=\left[200\left[\mathrm{f}\left(\frac{Y}{Y n}\right)-\mathrm{f}\left(\frac{Z}{Z n}\right)\right] *\left\{\mathrm{n} *\left[\mathrm{P} *\left(\frac{\mathrm{D} \text { gaz plasma } * \mathrm{~d} 1}{D \text { reaction gas } * \mathrm{~d} 2}\right)\right]\right\}\right.
\end{aligned}
$$

In order to be able to simulate the layer homogeneity, in the simulation mathematical model, yield formula for coating was modified with the addition of a new factor " $\mathrm{d}$ ". This is a dimensionless parameter and takes account of the gas dispersion in the room (the distance between the simulated point and the nozzles position through which the plasma and reaction gasses are dispersed).

In comparison with Sigmund original formula:

$$
Y(E)=\frac{0.04}{U} \alpha\left(\frac{M t}{M i}\right) \operatorname{Sn}(E)
$$

the formula used in the program for regulating the homogeneity becomes:

$$
Y(E)=\frac{0.04}{U} \alpha\left(\frac{M t}{M i * d}\right) \operatorname{Sn}(E)
$$

Complementary to the mathematical relations that form the core of the model other aspects must be considered too. Thus, a first element necessary to be taken in consideration is the sputtering yield. This is measured in $\mathrm{nm}$ of coating / $\mathrm{m}$ / min (the speed at which the sub-layer / glass sheet is transported in the experimental installation).

By convention the transport speed of the sub-layer in the industrial installations is about $1 \mathrm{~m} / \mathrm{min}$. The speed of production line can however be adjusted depending on the desired performance parameters for the final product, because it influences directly the coated layer thickness in every manufacturing cell (due to the fact that the technological system realizes a constant sputtering both in terms of quality and quantity, the time spent by the glass sheet in the sputtering area influences the coating thickness).

$$
Y(E)=\frac{X n m}{m}=\frac{X n m}{1}=X n m
$$

where $\mathrm{X}$ is the thickness of the coated layer.

In the same time, for correlating the results of experimental testing with the parameters for identifying the coated layers thickness CIELAB, in the mathematical model were included specific formalizations. Thus, if for example it is taken in consideration the coating with a single copper layer with a thickness of $\mathrm{X} \mathrm{nm}$, the light passed through this layer will have the coordinates:

$$
\begin{aligned}
& X^{*} c_{1} \mathrm{Cu}=\mathrm{L} * \mathrm{C} \\
& \mathrm{X}^{*} \mathrm{c}_{2} \mathrm{Cu}=\mathrm{a} * \mathrm{C} \\
& \mathrm{X}^{*} \mathrm{c}_{3} \mathrm{Cu}=\mathrm{b} * \mathrm{C}
\end{aligned}
$$

where $c_{1}, c_{2}, c_{3}$ are color characteristics of copper material.

If for example it is taken in consideration as a requirement getting a product with 3 layers of material, results that for obtaining the specific values of $\mathrm{L}_{3} * \mathrm{a}_{3} * \mathrm{~b}_{3} *$ the characteristics of the all 3 material layers must be added up in each of the three coordinates and must look after an equilibrium between their value and the layer thickness. 


$$
\begin{aligned}
& \mathrm{L}_{3} *=\left(\mathrm{L}_{2} * \mathrm{c}_{1} \mathrm{Cu} * \mathrm{X}\right)+\left(\mathrm{L}_{1} * \mathrm{c}_{1} \mathrm{Cu} * \mathrm{X}\right)+\left(\mathrm{L}_{0} * \mathrm{c}_{1} \mathrm{Cu} * \mathrm{X}\right) \\
& \mathrm{a}_{3} *=\left(\mathrm{a}_{2} * \mathrm{c}_{1} \mathrm{Cu} * \mathrm{X}\right)+\left(\mathrm{a}_{1} * \mathrm{c}_{1} \mathrm{Cu} * \mathrm{X}\right)+\left(\mathrm{a}_{0} * \mathrm{c}_{1} \mathrm{Cu} * \mathrm{X}\right) \\
& \mathrm{b}_{3} *=\left(\mathrm{b}_{2} * \mathrm{c}_{1} \mathrm{Cu} * \mathrm{X}\right)+\left(\mathrm{b}_{1} * \mathrm{c}_{1} \mathrm{Cu} * \mathrm{X}\right)+\left(\mathrm{b}_{0} * \mathrm{c}_{1} \mathrm{Cu} * \mathrm{X}\right)
\end{aligned}
$$

In fig. 11 it is represented in a simplified way the base principle of the mathematical model. The light beam, marked with nr. 1 having color coordinates for natural white light as they are described in the international standard D 65, passes the coated layer, marked with $\mathrm{nr}$. 2, on the sub-layer represented on the plane glass, marked with nr. 5. Starting from the initial color coordinates $\mathrm{L}^{*}, \mathrm{a}^{*}, \mathrm{~b}^{*}$ due to the refraction phenomenon, angle of refraction being marked with nr. 3, results the light beam, marked with 4 , having color coordinates $\mathrm{L}^{*} \mathrm{c}, \mathrm{a} * \mathrm{c}, \mathrm{b} * \mathrm{c}$.

Due to the fact that the developed formula is similar for the three coordinates, the only difference is the different initial value of the coordinates.

The coated layer of material by magnetron process is given by equation (14) where $\mathrm{P}$ is system input power measured in $\mathrm{KW} / \mathrm{h}$; D is plasma gas plasma gas flow introduced in system measured in s.s.c; $\mathrm{d}_{1 \text { is }}$ dimensionless material constant for plasma gas; $D$ is reactive gas flow introduced in system measured in s.s.c; $d_{2}$ is dimensionless material constant for reaction gas:

$$
(\mathrm{P} *[(\mathrm{D} \text { plasma gas* } \mathrm{d} 1) /(\mathrm{D} \text { reaction gas } * \mathrm{~d} 2)]
$$

\subsection{Experimental works on industrial scale flexible manufacturing line for thin layer magnetron sputtering deposition}

For each manufacturing cell there are already set some specific features of the flexible manufacturing lines by producer including: typical flexible cell dimensions: $80 \times 15 \times 5 \mathrm{~m}(\mathrm{~L} \times \mathrm{W} \times \mathrm{H})$; minimum industrial room height: 6,0 m; maximum size of glass substrate according to industry standards PLF and DLF: 3,66 × 2,54 m2; 6,00 $\times 3,30 \mathrm{~m}^{2}$; minimum dimensions of the glass layer: $0,8 \times 0,30 \mathrm{~m}^{2}$; usual glass substrate thickness: $2.0-12 \mathrm{~mm}$; interior width of the processing compartment: $850 \mathrm{~mm}$ [7]. The main operating parameters to be set include: system input power applied on the cathodes expressed in Kw; (by increasing the power, material deposition rate increases in direct proportion to the introduced system power); plasma gas used, usually Helium, Neon, Argon, Krypton, Xenon being used. (Depending on the molar mass of this material, the target is bombarded with particles with higher energy resulting in greater impact, a higher spraying rate and a high deposition rate); reaction gas (in some products, in layers can be found beside metals also oxide or nitride layers. To obtain these layers oxygen or nitrogen is introduced in system which reacts with the sprayed on the surface of the targets, optical and electrical proprieties of coated films being dependent by the nature and flow of these gases [11]).

A comparison between simulation and experimental sets of results performed for four types of materials deposed $\mathbf{M}_{1}$,

\begin{tabular}{|c|c|c|c|c|c|c|c|c|c|c|c|c|}
\hline date & $\begin{array}{c}\mathrm{a}^{*} \\
\text { simulation }\end{array}$ & $\begin{array}{l}\mathrm{a}^{*} \\
\text { error }\end{array}$ & $\begin{array}{c}\mathrm{a}^{*} \\
\text { experim. }\end{array}$ & $\begin{array}{c}\text { calculus } \\
\text { deviation } \mathrm{a}^{*}\end{array}$ & $\begin{array}{c}\mathrm{b}^{*} \\
\text { simulation }\end{array}$ & $\begin{array}{l}b^{*} \\
\text { error }\end{array}$ & $\begin{array}{c}b^{*} \\
\text { experim. }\end{array}$ & $\begin{array}{c}\text { calculus } \\
\text { deviation } b^{*}\end{array}$ & $\begin{array}{l}\mathrm{M}_{1} \\
\mathrm{~kW}\end{array}$ & $\begin{array}{l}\mathrm{M}_{2} \\
\mathrm{~kW}\end{array}$ & $\begin{array}{l}\mathrm{M}_{3} \\
\mathrm{~kW}\end{array}$ & $\begin{array}{l}\mathrm{M}_{4} \\
\mathrm{~kW}\end{array}$ \\
\hline 24.03.2015 & 3.529394 & 0.029394 & 3.5 & -0.029394 & -8.970605 & -0.470605 & -8.5 & 0.470605 & 96 & 288 & 25.3 & 336 \\
\hline 26.04 .2015 & 3.136491 & 0.636491 & 2.5 & -0.636491 & -10.303750 & -0.803750 & -9.5 & 0.803750 & 92 & 279 & 24.5 & 336 \\
\hline 13.05 .2015 & 0.166666 & 1.333333 & 1.5 & 1.333333 & -8.893617 & -0.393617 & -8.5 & 0.393617 & 92 & 279 & 19 & 375 \\
\hline 15.06 .2015 & 3.905788 & 1.105788 & 2.8 & -1.105788 & -9.572830 & -0.572830 & -9 & 0.572830 & 82 & 237 & 25.5 & 336 \\
\hline 18.07 .2015 & 4.973798 & 2.473798 & 2.5 & -2.473798 & -8.466442 & 1.033557 & -9.5 & -1.033557 & 100 & 252 & 24.5 & 336 \\
\hline
\end{tabular}
$\mathrm{M}_{2}, \mathrm{M}_{3}, \mathrm{M}_{4}$ (for experimentally works performed along four months, only partially sets of results being included in the paper) are presented in table 3 and table 4 . Relative error between simulation results and experimentally results as well as appropriate deviations are also presented in table 4 and table 5 as well as fig. 12, fig 13 and fig.14.

Table 5. Simulation and experimental works set of results and relative error between them and simulation deviation

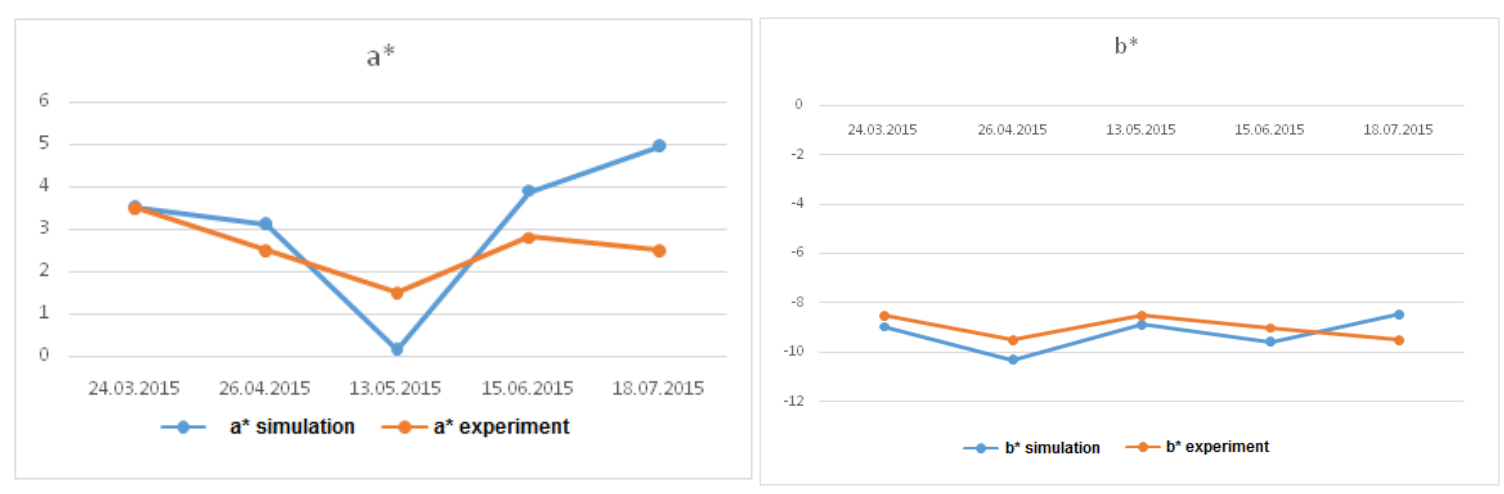




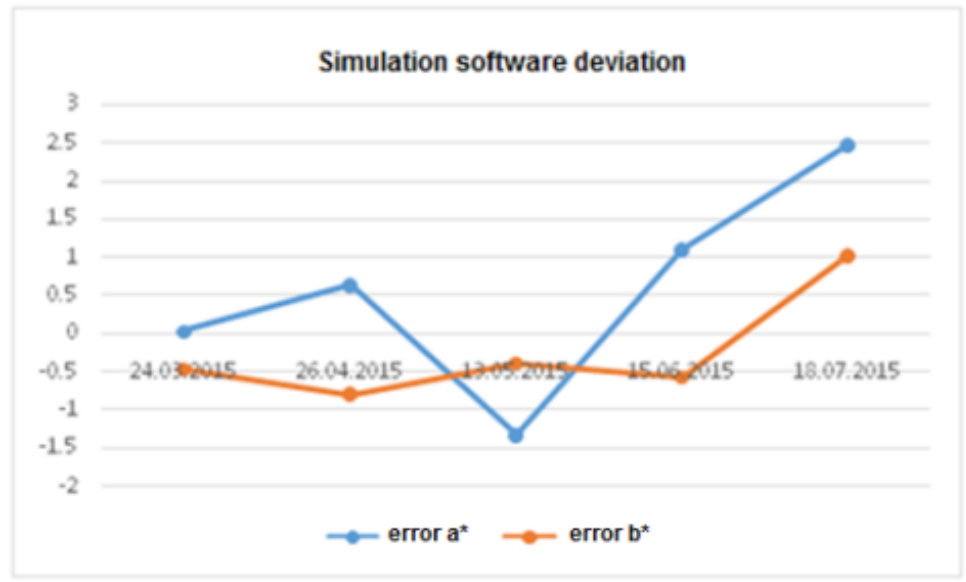

Fig. 12 a. Comparison between simulation and experimental results for $\mathrm{a}^{*}, \mathrm{~b}^{*}$ values. Simulation software deviation

\section{Conclusions}

Use of the simulation models presented in the literature until now is not possible in the industrial environment because the laboratory and the industrial experimental equipment / manufacturing facilities are different. The laboratory experimental equipment is usually used to completely characterize a singular experiment already performed by using a single pulverization of a single deposition material type. Besides, in the industrial environment the manufacturing lines are including a large number of magnetron sputtering cells / chambers that are interconnected, in order to allow successively depositing of different materials in specific conditions of processing gases' pressure and substrate speeds. Another main difference between ways of conducting experiments is due to the experiments duration difference: the experimental laboratory equipment is dedicated to the study of the reactions lasting only a few seconds, comparatively to the real industrial scale equipment where the reaction is continuous for several days. These issues have been solved by present paper specific approach. As result, present paper illustrates a new approach regarding the study of magnetron sputtering discharge process on an industrial scale flexible manufacturing line. For this purpose a new mathematical model and simulation software have been developed. Based on this new mathematical model and simulation software, the thin layer glass coating by magnetron sputtering processes performed in industrial environment has been theoretically studied and the results have been validated by experimental research conducted on the industrial site.

Developing a simulator for the whole process of facilities at industrial scale represents a way of studying the possibilities to optimize the technological processes, allowing time shortage of facility setup for realizing a new product, from few weeks to few hours or even less. Using the simulator presented in this paper a significant improvement of product performance parameters is possible, regarding the reducing of the quantity of consumed energy, coating materials and rate of non conform product batches. Major difference in experimental approach of vacuum deposition processes for laboratory research equipment (presented in the literature) and industrial processing equipment (presented in current paper) consist in focusing on investigating the interaction between the target material and particles as well as particle trajectory in vacuum environment for laboratory equipment, respectively on effective deposition process and the thickness and uniformity of the deposed layers on the substrate for industrial equipment.

A second major aspect of the new presented approach consist in mathematical formulation used to simulate the final result of the deposition process, which in present paper is illustrated using the specific industrial standards(CIELAB) to characterize the light passing through the deposited layer on the substrate, this approach being necessary in order to create first the possibility to validate the mathematical formalization by experimental research performed on real industrial scale production equipment and second to use specific industrial means to characterize the final product obtained in such type of equipment (optic photometer). For this purpose, the operating principle of simulation software is first to predict the thickness of the layer deposed in the magnetron process based on the international system D65 and, then evaluate the layer thickness starting from the measured white light coordinates, (computing the color of light resulted from passing through the deposed layer) by mean of an optic photometer used for measuring the value of the light passing through the substrate and deposed layer. All simulation results were validated on an industrial flexible manufacturing line. As result of applying this new concept on industrial scale processing system an improvement of the deposition process control has been obtained leading to an increasing of the uniformity of deposed layers from $\pm 10 \%$ to $\pm 2 \%$ and differences between theoretical and applicative vaporizing energies have been identified for two materials.

\section{Acknowledgments}

This work was partially supported by the strategic grant POSDRU/159/1.5/S/137070 (2014) of the Ministry of National Education, Romania, co-financed by the European Social Fund - Investing in People, within the Sector Operational Program Human Resources Development 2007-2013”. 


\section{References}

[1] I. Spataru - Contributions to modeling and simulation of flexible manufacturing systems" PhD Thesis, Politehnica University of Bucharest, public presentation september 2016, Bucharest

[2] N. Brenning, D. Lundin, M. A. Raadu, C. Huo, C. Vitelaru, G. D. Stancu, T. Minea , and U. Helmersson, Understanding deposition rate loss in high power impulse magnetron sputtering, Plasma sources science \&amp; technology (Print), (21), 2, 2012, ID no. 025005, http://dx.doi.org/10.1088/0963-0252/21/2/025005

[3] Murtaza Saleem, Overview of Magnetron Sputtering System (DaON 1000S), Lahore University of Management Sciences, http://physlab.org/wp-content/uploads/2016/04/Murtaza_presentation.pdf

[4] https://en.wikipedia.org/wiki/Sputtering

[5] V. Kozlov, E. Yadin, G. Taiminsh, and V. Fomin, New vacuum equipment for multilayer coating deposition on large area glass, Society of Vacuum Coaters 505/856-7188, 50th Annual Technical Conference Proceedings (2007) ISSN 0737-5921, 2007

[6] P.Sigmund, "Sputtering by ion bombardment: theoretical concepts", Chapter 2, in Sputtering by particle bombardment I, edited by R. Behrish, Volume 47 of the series Topics in Applied Physics pp 9-71, Springer-Verlag, 2005

[7] *** Solutions for large area coating, Leybold Optics documentation 2016, Bühler Alzenau GmbH, www.buhlergroup.com

[8] *** CIE 15 - Technical Report - International comission on illumination, ISBN 3-901-906-33-9, Washington, USA

[9] S. Mahieu, G. Buyle, D. Depla, S. Heirwegh, P. Ghekiere, R. De Gryse, "Monte Carlo simulation of the transport of atoms in DC magnetron sputtering", in Nuclear Instruments and Methods in Physics Research Section B: Beam Interactions with Materials and Atoms, Volume 243, Issue 2, 2006, Elsevier

[10] S. Van Steenberge, W.P. Leroy, D. Depla, "Influence of oxygen flow and film thickness on the texture and microstructure of sputtered ceria thin films", in Thin Solid Films, Volume 553, 2014, Elsevier

[11] M. Bender, W. Seelig, C. Daube, H. Frankenberger, B. Ocker, J. Stollenwerk, "Dependence of oxygen flow on optical and electrical properties of DC-magnetron sputtered ITO films", in Thin Solid Films, Volume 326, Issues 12, 1998, Elsevier 